\title{
Overexpression of IncRNA TUSC7 reduces cell migration and invasion in colorectal cancer
}

\author{
HAIXIA ZHANG, YANLI SONG, CHANGQING YANG and XIANZHENG WU \\ Department of Emergency, Tongji Hospital Affiliated to Tongji University, Shanghai 200333, P.R. China
}

Received September 11, 2018; Accepted March 7, 2019

DOI: $10.3892 /$ or.2019.7106

\begin{abstract}
Colorectal cancer (CRC) is a highly heterogeneous disease worldwide. Long non-coding RNA (lncRNA) tumor suppressor candidate 7 (TUSC7) plays a crucial role in the development of several cancers. However, the role of TUSC7 in the tumorigenesis of CRC has not been explored. The TUSC7-overexpressing CRC cell lines SW480 and CaCo-2 were generated to investigate the effects of TUSC7 on the growth, migration, invasion and epithelial-mesenchymal transition (EMT) of CRC cells. CCK-8, wound-healing and Transwell assays were used to evaluate CRC cell proliferation, migration and invasion. The mRNA and protein expression of TUSC7 were detected by quantitative real-time PCR and immunoblotting, respectively. In the present study, we observed that the expression of TUSC7 was decreased in CRC cells compared to the expression in the normal colon epithelial cell line NCM460. Moreover, overexpression of TUSC7 inhibited CRC cell proliferation, metastasis, invasion and EMT. These findings indicated that TUSC7 is involved in CRC development.
\end{abstract}

\section{Introduction}

Colorectal cancer (CRC) is one of the most aggressive cancers in the world and is associated with a high mortality rate (1-3). Notably, an increased rate of CRC has been reported in many countries (4-6). Despite improvements in diagnostic and treatment techniques, the 5-year relative survival rates are still low in CRC patients $(7,8)$. Therefore, a better understanding of the molecular mechanisms of CRC initiation and progression may promote the development of new treatments for CRC patients.

Recently, several of long non-coding RNAs (IncRNAs) have been regarded as important modulators in cancer progression and development (9-12). It has been reported that the IncRNA

Correspondence to: Dr Xianzheng Wu, Department of Emergency, Tongji Hospital Affiliated to Tongji University, 389 Xincun Road, Shanghai 200333, P.R. China

E-mail: xianzhengwubio@sohu.com

Keywords: TUSC7, colorectalcancer,invasion, migration, epithelialmesenchymal transition promoter of CDKN1A antisense DNA damage-activated RNA(PANDAR) is involved in the development and progression of many cancers, including CRC (13-15). Moreover, lncRNA PANDAR was revealed to inhibit CRC apoptosis and induce CRC growth via the epithelial-mesenchymal transition (EMT) pathway (16). These results demonstrated that lncRNAs could be used as new therapeutic targets for CRC treatment $(17,18)$. Hence, to investigate the molecular mechanisms that mediate cancer development, increased efforts are required to explain the role of lncRNAs in CRC.

Tumor suppressor candidate 7 (TUSC7) is an lncRNA that has been revealed to be downregulated in CRC tissues (19). Furthermore, TUSC7 inhibited CRC cell proliferation by sponging miR-211-3p (19). The expression of TUSC7 in CRC cells was revealed to reduce cell growth, whereas the low expression of TUSC7 indicated poor prognosis of CRC patients (20). However, little is known about the expression and the role of TUSC7 in CRC cell migration and invasion.

To date only a few studies have analyzed the possible role of TUSC7 in CRC $(19,20)$. The aim of the present study was to analyze the precise role of TUSC7 in CRC progression.

\section{Materials and methods}

Cell culture. The HCT116, COLO205, HT29, SW480 and CaCO-2 cells and the normal colon epithelial cell line NCM460 were seeded in Dulbecco's modified Eagle's medium (DMEM) with $10 \%$ fetal bovine serum (FBS), 1\% penicillin G-streptomycin (Gibco; Thermo Fisher Scientific, Inc., Waltham, MA, USA) at $37^{\circ} \mathrm{C}$ in an incubator with $5 \% \mathrm{CO}_{2}$.

$R N A$ preparation, reverse transcription, and quantitative real-time PCR. RNA was extracted from cells by TRIzol reagent (Invitrogen; Thermo Fisher Scientific, Inc.). RNA was reverse-transcribed by a reverse transcription kit (Takara Biotechnology Co., Ltd., Dalian, China) according to the manufacturer's protocol. Real-time PCR expression was assessed by SYBR ${ }^{\circledR}$ PremixEx Taq ${ }^{\mathrm{TM}}$ (Takara Biotechnology Co., Ltd.). The PCR primers used were as follows (19): TUSC7 forward, 5'-GGAAACAGAAGGCACCTCA-3' and reverse, 5'-TCTCAGAGGTCAAACAGGCA-3'; GAPDH forward, 5'-GTCAACGGATTTGGTCTGTATT-3' and reverse, 5'-AGT CTTCTGGGTGGCAGTGAT-3'. Relative quantification of TUSC7 was performed by the $2^{-\Delta \Delta C q}$ method (21). All reactions were repeated in triplicate. 
Overexpression of TUSC7. The overexpression vector pCDNA-TUSC7 and the empty vector pCDNA-N1 (NC) were obtained from Genomeditech Co., Ltd. (Shanghai, China). Cells (at $\sim 70 \%$ confluence) were transfected with Lipofectamine $^{\text {TM }} 3000$ reagent (Life Technologies; Thermo Fisher Scientific, Inc.) following the manufacturer's protocols for $24 \mathrm{~h}$. The expression of TUSC7 was determined by qRT-PCR.

Cell proliferation assay. Cell proliferation was detected by the Cell Counting Kit-8 (CCK-8; Dojindo Molecular Technologies, Inc., Kumamoto, Japan) assay following the manufacturer's protocol. In brief, the transfected cells $\left(1 \times 10^{5}\right.$ cells $)$ were seeded in 96-well plates, and then CCK-8 solution (10 $\mu \mathrm{l})$ was added for $2 \mathrm{~h}$. The absorbance was measured by an ELISA reader (Molecular Devices Sunnyvale, CA, USA) at $450 \mathrm{~nm}$.

Cell cycle analysis. Cells $\left(1 \times 10^{6}\right)$ were seeded in 6-well plates for $24 \mathrm{~h}$. Then, cells were loaded with propidium iodide (PI; $100 \mu \mathrm{l}$ ) for $30 \mathrm{~min}$ at $4^{\circ} \mathrm{C}$ in the dark. The cell-cycle distribution was determined by flow cytometry.

Invasion and migration assay. The Transwell chamber was obtained from Corning Inc., (Corning, NY, USA) for the cell invasion and migration assays. For the cell invasion assay, the chamber was precoated with $30 \mu \mathrm{l}$ of Matrigel (BD Biosciences, San Jose, USA) for $1 \mathrm{~h}$. Cells ( $5 \times 10^{5}$ cells) were maintained in the upper chamber, and the lower chamber contained DMEM (500 $\mu \mathrm{l})$ supplemented with $20 \%$ FBS for $12 \mathrm{~h}$ at $37^{\circ} \mathrm{C}$. The invaded cells were stained with calcein-AM, and the invaded cells were counted under a fluorescence microscope (magnification, x100). For the cell migration assay, cells $\left(5 \times 10^{5}\right.$ cells) were seeded into the upper chamber containing DMEM $(500 \mathrm{ml})$ supplemented with $20 \%$ FBS for $12 \mathrm{~h}$ at $37^{\circ} \mathrm{C}$. The migrated cells were stained with calcein-AM, and the migrated cells were counted under a fluorescence microscope (magnification, $\mathrm{x} 100$ ).

Wound-healing assay. Cells were cultured in 6-well plates to $90-95 \%$ confluence. Wounds were generated with a plastic scraper, then cells were washed with phosphate-buffered saline (PBS) twice and incubated in a FBS free medium for $24 \mathrm{~h}$, images were observed by a light microscope.

Western blot analysis. The SW480 and CaCO-2 cells were collected and lysed in RIPA buffer (EMD Millipore, Temecula, CA, USA). The protein concentration was determined using the BCA method (Beyotime Institute of Biotechnology, Beijing, China). Proteins (40 $\mu \mathrm{g})$ were separated by using $12 \%$ SDS-polyacrylamide gel electrophoresis (SDS-PAGE) and were then transferred to $0.22 \mu \mathrm{m}$ nitrocellulose membranes (EMD Millipore). The membranes were blocked with $5 \%$ non-fat milk for $1 \mathrm{~h}$ at room temperature. Then, membranes were incubated with the E-cadherin (dilution 1:1,000; cat. no. 3195; Cell Signaling Technology Inc., Danvers, MA, USA), vimentin (dilution 1:1,000; cat. no. 5741; Proteintech Group, Inc., Chicago, IL, USA) overnight at $4^{\circ} \mathrm{C}$. Membranes were then incubated with a horseradish peroxidase-linked secondary antibody (mouse anti-rabbit IgG-FITC; dilution 1:1,000; cat. no. sc-2359; Santa Cruz Biotechnology,

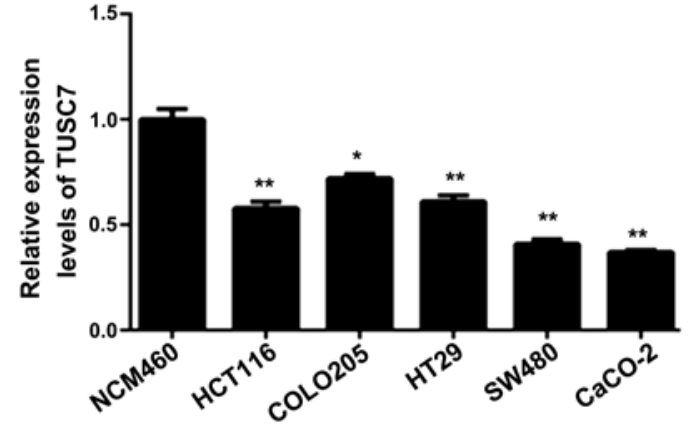

Figure 1. Expression of TUSC7 in colorectal cancer cells compared to the expression in the NCM460 normal colon epithelial cells. Each experiment was repeated three times. Data are presented as the mean $\pm \mathrm{SD}$. ${ }^{*} \mathrm{P}<0.05$, ${ }^{* *} \mathrm{P}<0.01$ compared to NCM460 cells. TUSC7, tumor suppressor candidate 7; $\mathrm{SD}$, standard deviation.

Dallas, TX, USA) for $1 \mathrm{~h}$ at room temperature. The blots were visualized by using enhanced chemiluminescence ECL (Pierce Biotechnology; Thermo Fisher Scientific, Inc.).

Statistical analysis. All data were obtained from three independent experiments. Data were analyzed using SPSS 17.0 (SPSS, Inc., Chicago, IL, USA). The statistical significance of the differences between groups was determined using t-tests. Data are expressed as the means \pm standard deviations (SD). Differences with $\mathrm{P}$-values $<0.05$ were considered to indicate a statistically significant difference.

\section{Results}

The expression of TUSC7 decreases in CRC cells. The expression of TUSC7 in HCT116, COLO205, HT29, SW480 and CaCo-2 cells was lower than that in the NCM460 cells ( $\mathrm{P}<0.05$; Fig. 1), which indicated that TUSC7 plays a key role in CRC progression. Since TUSC7 expression in SW480 and CaCO-2 cells was lower than the other cell lines, SW480 and $\mathrm{CaCO}-2$ cells were selected in the subsequent experiments.

TUSC7 inhibits SW480 and CaCO-2 cell proliferation. To overexpress TUSC7, a lentiviral vector was used in SW480 and CaCO-2 cells. As revealed in Fig. 2A, TUSC7 expression was increased in SW480 and CaCO-2 cells. The CCK-8 assay revealed that overexpression of TUSC7 decreased the proliferation rate of both SW480 (data not shown) and CaCO-2 cells (Fig. 2B).

TUSC7 induces SW480 and CaCO-2 cell cycle arrest. To explore whether TUSC7 regulates the cell cycle of CRC cells, PI staining and flow cytometric analysis were used. As indicated in Fig. 3, overexpression of TUSC7 notably increased G1 phase cell cycle arrest, whereas the $\mathrm{S} / \mathrm{G} 2$ phase was reduced in both SW480 and CaCO-2 cells.

TUSC7 inhibits SW480 and CaCO-2 cell migration. To explain the role of TUSC7 in CRC cell metastasis, Transwell and wound-healing assays were employed. Compared with the control group, overexpression of TUSC7 significantly reduced the migration ability of both SW480 and CaCO-2 cells (Fig. 4A and B). 

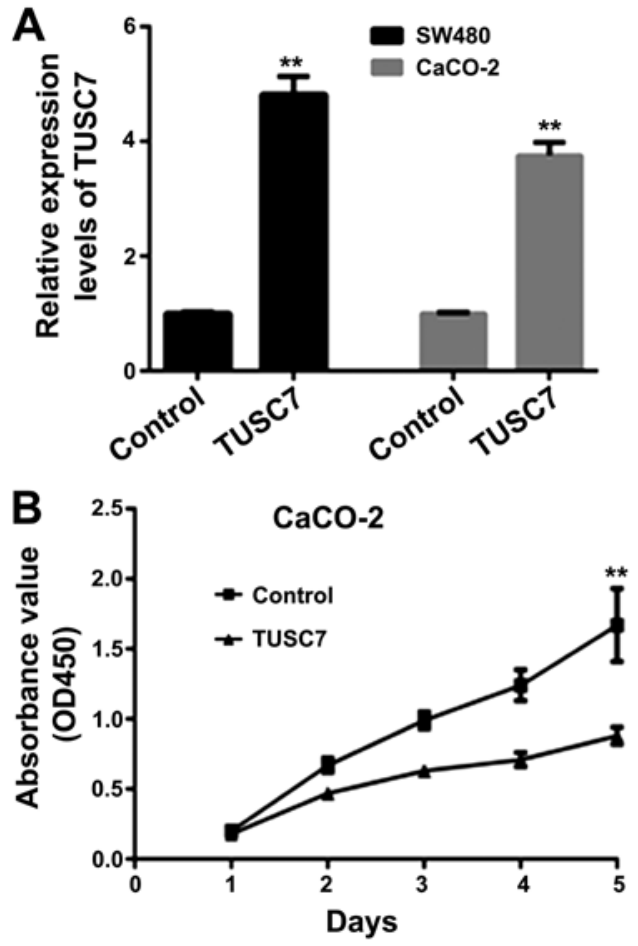

Figure 2. Overexpression of TUSC7 in CRC cells decreases cell proliferation. (A) Real-time PCR assay revealed that the mRNA levels of TUSC7 were significantly upregulated after transfection with the TUSC7 overexpression plasmid. (B) The CCK-8 assay was performed after TUSC7 overexpression in $\mathrm{CaCO}-2$ cells. Each experiment was repeated three times. Data are presented as the mean $\pm \mathrm{SD} .{ }^{* *} \mathrm{P}<0.01$ compared to the control. TUSC7, tumor suppressor candidate 7; CRC, colorectal cancer; CCK-8, Cell Counting Kit-8; $\mathrm{SD}$, standard deviation.
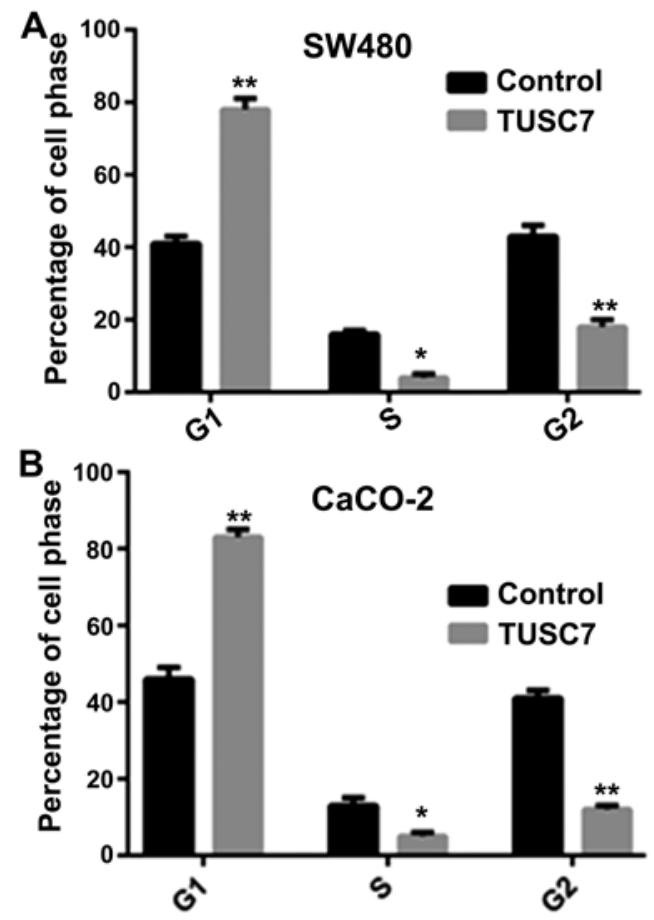

Figure 3. Overexpression of TUSC7 inhibits the cell cycle progression of CRC cells. The percentage of cells in each phase of the cell cycle was detected by flow cytometry after transfection with the TUSC7 overexpression plasmid and the control plasmid in (A) SW480 and (B) CaCO-2 cells. Each experiment was repeated three times. Data are presented as the mean $\pm \mathrm{SD}$. ${ }^{*} \mathrm{P}<0.05$, ${ }^{* *} \mathrm{P}<0.01$ compared to the control. TUSC7, tumor suppressor candidate 7; CRC, colorectal cancer; SD, standard deviation.
The migration abilities of CRC cells were also assessed by a wound-healing assay. The wound-healing assay exhibited similar results. Compared with the control group, overexpression of TUSC7 resulted in significantly decreased migration abilities of both SW480 (Fig. 4C and D) and CaCO-2 cells (Fig. 4E and F), suggesting that overexpression of TUSC7 inhibited the migration of CRC cells.

TUSC7 inhibits SW480 and CaCO-2 cell invasion. The invasion ability of CRC cells was evaluated by a Transwell invasion assay. Compared with the control group, overexpression of TUSC7 markedly reduced the invasion ability of CRC cells (Fig. 5). These results suggested that TUSC7 plays a key role in CRC metastasis.

TUSC7 suppresses EMT in SW480 and CaCO-2 cells. It is well known that EMT plays a key role in CRC cell migration and invasion. Therefore, we investigated whether TUSC7 affects the EMT of CRC. The results of the qRT-PCR (Fig. 6A and B) and western blot analysis (Fig. 6C) revealed that E-cadherin expression was increased and vimentin expression was suppressed in the cells overexpressing TUSC7 compared to the expression levels of the control group. Hence, this finding revealed that TUSC7 inhibited the EMT of CRC.

TUSC7 inhibits EMT in SW480 and CaCO-2 cells via activation of ZEB1. To determine whether ZEB1 has a mediatory effect on the TUSC7-dependent suppression of EMT, we used siRNA to reduce the expression of ZEB1. The data revealed that the expression of E-cadherin and vimentin were restored by siZEB1, which indicated the initiation of the EMT of CRC (Fig. 6D). These results indicated that TUSC7 inhibited the EMT of CRC via ZEB1 expression.

\section{Discussion}

A significant association between aberrant tumor suppressor candidate 7 (TUSC7) expression and cancer development, including squamous cell carcinoma (22), glioma (23), gastric cancer $(24)$ and other types of cancer $(25,26)$ has been demonstrated. In a previous study, TUSC7 increased colorectal cancer (CRC) cell proliferation by sponging miR-211-3p (19). To the best of our knowledge, there are no previous studies that have focused on the role of TUSC7 expression in CRC cell migration and invasion.

The expression level of TUSC7 has been associated with cancer development and progression (19). Consistent with these previous findings, we demonstrated that TUSC7 was downregulated in CRC cells compared to its expression in NCM460 cells. To explore the role of TUSC7 in CRC cells, we used an overexpression assay in both SW480 and CaCo-2 cells. As predicted, overexpression of TUSC7 suppressed CRC cells, as revealed by the CCK- 8 assay. Moreover, overexpression of TUSC7 inhibited CRC cells to the S/G2 phase and increased the number of CRC cells in the G1 phase. These data have also been reported in a study by $\mathrm{Xu}$ et al (19). Thus, our findings indicated that TUSC7 decreased CRC cell proliferation.

It has been revealed that the migration ability of cancer is associated with TUSC7 expression, suggesting that TUSC7 works as a key tumor suppressor in many types of 
A

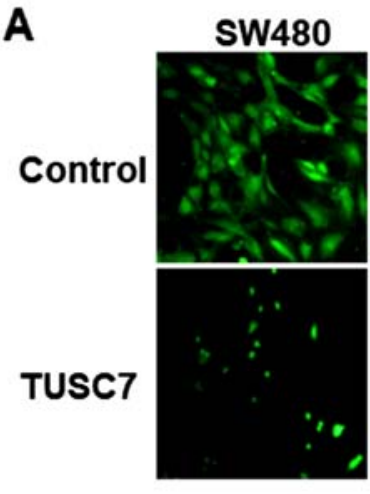

C

Control

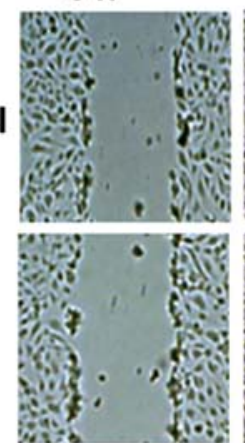

E

Control

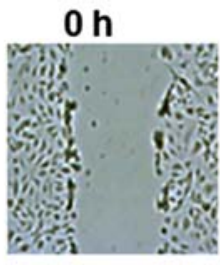

TUSC7

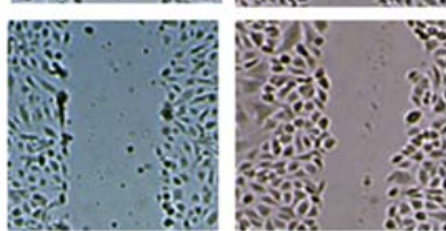

$24 \mathrm{~h}$
B
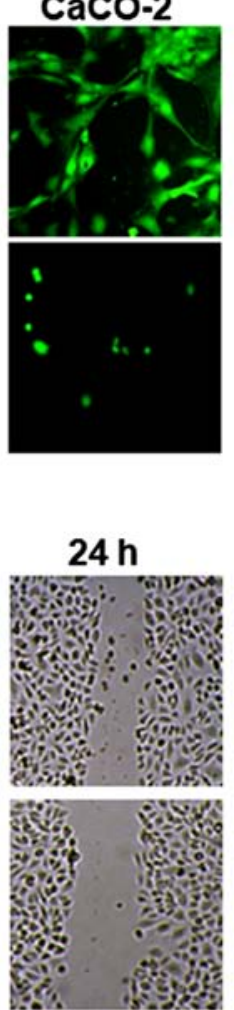

D

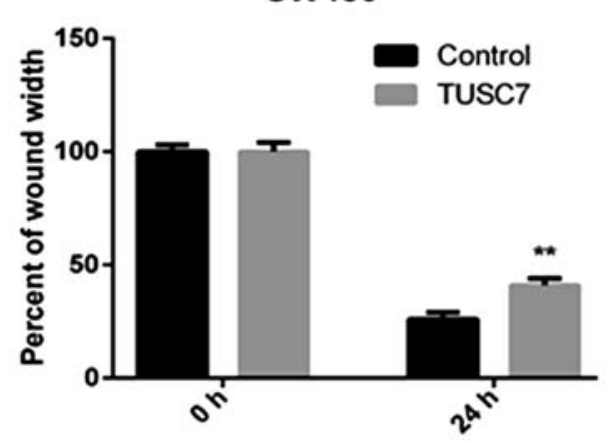

F

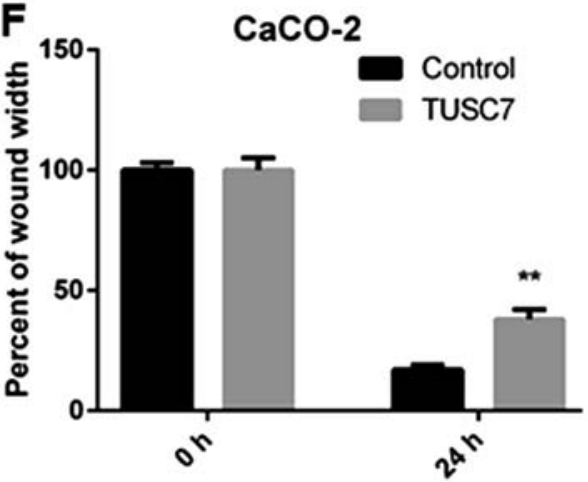

$24 \mathrm{~h}$

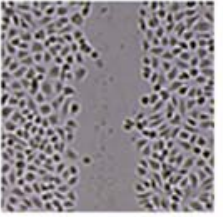

a

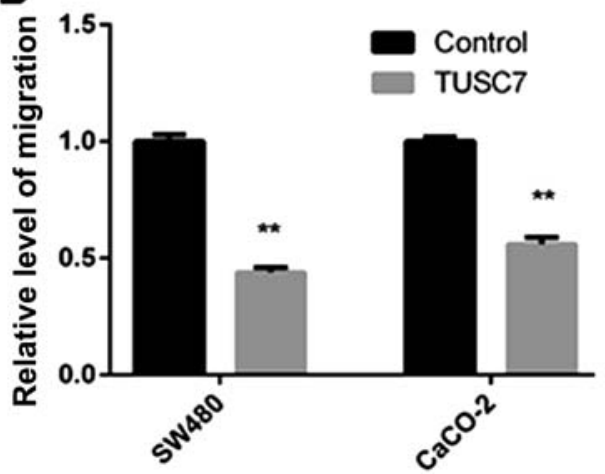

SW480

Figure 4. Overexpression of TUSC7 inhibits the migration of CRC cells. (A) Photomicrograph showing migrated cells from the control and TUSC7-overexpressing SW480 and CaCO-2 cells. (B) Quantified data for the Transwell migration assay described in A. (C and E) Photomicrograph of the wound-healing assay from the control and TUSC7-overexpressing SW480 and CaCO-2 cells. (D and F) Quantified data for the wound-healing assay described in C and E. Each experiment was repeated three times. Data are presented as the mean $\pm \mathrm{SD}$. ${ }^{* *} \mathrm{P}<0.01$ compared to the control. TUSC7, tumor suppressor candidate 7 ; $\mathrm{CRC}$, colorectal cancer; SD, standard deviation.

A

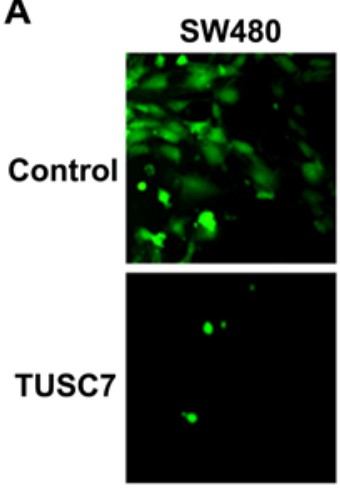

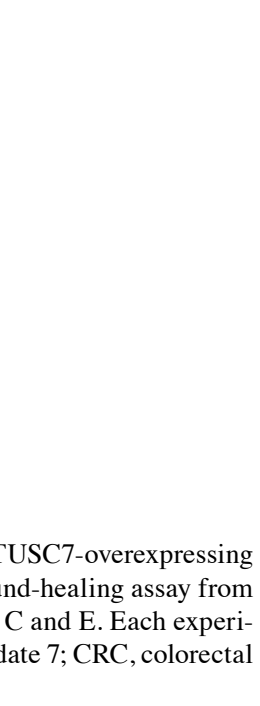


A

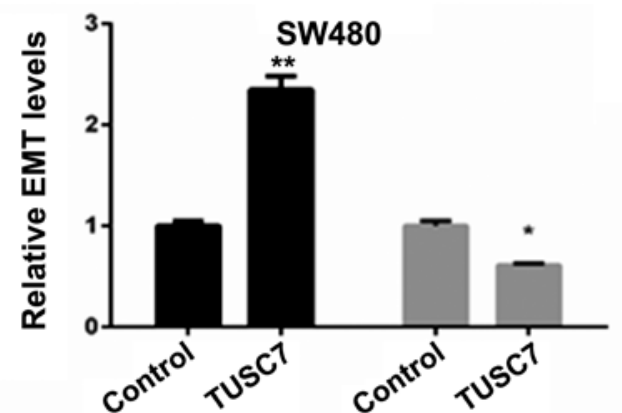

E-cadherin

Vimentin

B

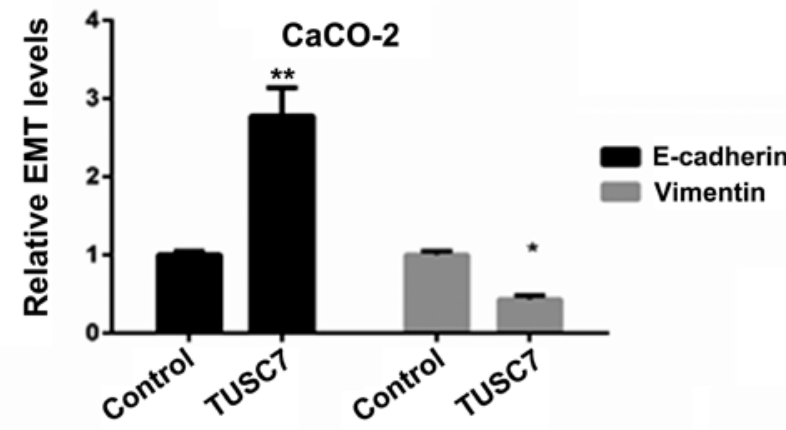

C
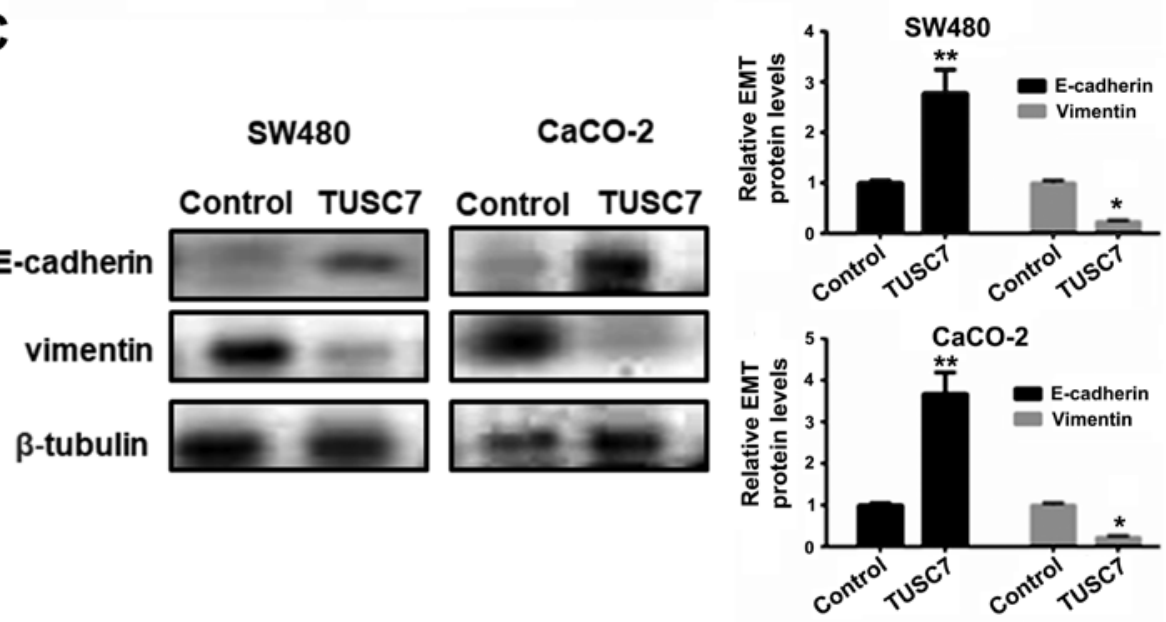

D

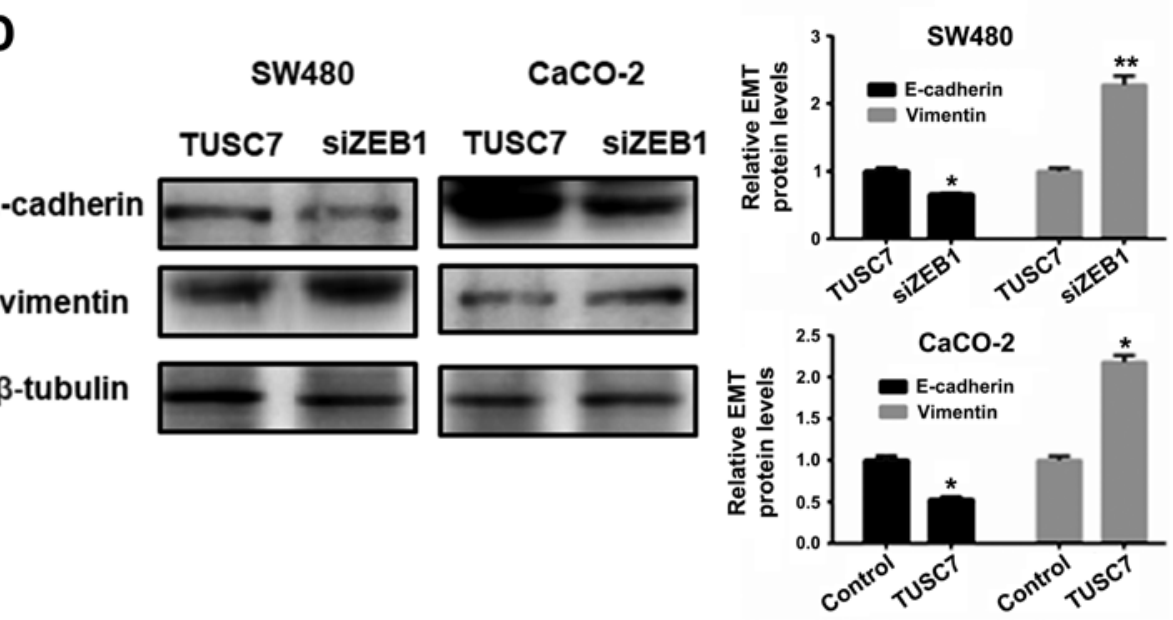

Figure 6. Overexpression of TUSC7 inhibits the EMT of CRC cells. (A and B) Real-time PCR assays revealed the mRNA levels of EMT after transfection with the TUSC7-overexpressing plasmid and the control plasmid. (C) An immunoblotting assay was performed in the control and TUSC7-overexpressing SW480 and CaCO-2 cells. (D) An immunoblotting assay was performed in TUSC7-overexpressing and siZEB1 SW480 and CaCO-2 cells. Each experiment was repeated three times. Data are presented as the mean $\pm \mathrm{SD}$. $\mathrm{P}<0.05$ compared to the control. ${ }^{\text {** }} \mathrm{P}<0.01$ compared to the control. TUSC7, tumor suppressor candidate 7; EMT, epithelial-mesenchymal transition; CRC, colorectal cancer; SD, standard deviation.

cancer $(25,27,28)$. In the present study, we found that overexpression of TUSC7 significantly reduced CRC cell migration.
These data revealed that TUSC7 was involved in the migration ability of CRC cells. 
EMT is a key process that stimulates the mesenchymal state and induces the migration and invasion of cancer cells $(29,30)$. Recent findings have revealed that lncRNAs are involved in the EMT (31-33). Some long non-coding RNAs (lncRNAs) promote EMT whereas some lncRNAs suppress EMT. IncRNA CPS1-IT1 was revealed to inhibit EMT and the migration of CRC by inactivating HIF-1 $\alpha$ in vivo and in vitro $(34,35)$. IncRNA AB073614 stimulated the EMT of CRC cells via the JAK/STAT3 signaling pathway (36). In this study, we detected EMT biomarkers of CRC cells by qRT-PCR and western blot analysis. Notably, the data revealed that the expression level of TUSC7 was positively associated with the expression of E-cadherin and negatively associated with the expression of vimentin in CRC cells. It was revealed that TUSC7 suppressed the EMT in CRC cells. ZEB1 is a key regulator in the invasion and metastasis of cancer cells by inducing the EMT of CRC. Aberrant levels of ZEB1 have been found in different types of tumors, including hepatocellular carcinoma (37), breast cancer (38) and CRC (39). The association of ZEB1 with CRC development has been widely investigated, and this study suggested that knockdown of ZEB1 suppressed the inhibition of the EMT of CRC associated with TUSC7.

TUSC7 inhibited CRC cell proliferation, migration, invasion and EMT, indicating that TUSC7 could be a potential tumor suppressor in CRC. Although our results provide important insights into these processes, the roles of TUSC7 in in vivo studies are required to further confirm these data.

\section{Acknowledgements}

Not applicable.

\section{Funding}

No funding was received.

\section{Availability of data and materials}

The datasets supporting the conclusions of this article are included within the article.

\section{Authors' contributions}

HZ, YS and CY conceived of the idea, designed the study, performed research, analyzed and interpreted data and wrote the manuscript. CY and XW analyzed data. CY confirmed statistical analyses. XW revised the manuscript. All authors read and approved the manuscript and agree to be accountable for all aspects of the research in ensuring that the accuracy or integrity of any part of the work are appropriately investigated and resolved.

\section{Ethics approval and consent to participate}

The present study was approved by the Ethics Committees of Tongji Hospital Affiliated with Tongji University.

\section{Patient consent to participate}

Not applicable.

\section{Competing interests}

The authors declare that they have no competing interests.

\section{References}

1. Berian JR, Cuddy A, Francescatti AB, O'Dwyer L, Nancy You Y, Volk RJ and Chang GJ: A systematic review of patient perspectives on surveillance after colorectal cancer treatment. J Cancer Surviv 11: 542-552, 2017.

2. Fuccio L, Repici A, Hassan C, Ponchon T, Bhandari P, Jover R, Triantafyllou K, Mandolesi D, Frazzoni L, Bellisario C, et al: Why attempt en bloc resection of non-pedunculated colorectal adenomas? A systematic review of the prevalence of superficial submucosal invasive cancer after endoscopic submucosal dissection. Gut 67: 1464-1474, 2018.

3. Gkegkes ID, Minis EE and Iavazzo C: Dermatomyositis and colorectal cancer: A systematic review. Ir J Med Sci 187: 615-620, 2018.

4. Fang JY, Dong HL, Sang XJ, Xie B, Wu KS, Du PL, Xu ZX, Jia XY and Lin K: Colorectal cancer mortality characteristics and predictions in China, 1991-2011. Asian Pac J Cancer Prev 16: 7991-7995, 2015.

5. Huang HY, Shi JF, Guo LW, Bai YN, Liao XZ, Liu GX, Mao AY, Ren JS, Sun XJ, Zhu XY, et al: Expenditure and financial burden for the diagnosis and treatment of colorectal cancer in China: A hospital-based, multicenter, cross-sectional survey. Chin J Cancer 36: 41, 2017.

6. Ivanova JI, Saverno KR, Sung J, Duh MS, Zhao C, Cai S, Vekeman F, Peevyhouse A, Dhawan R and Fuchs CS: Real-world treatment patterns and effectiveness among patients with metastatic colorectal cancer treated with ziv-aflibercept in community oncology practices in the USA. Med Oncol 34: 193, 2017.

7. Väyrynen JP, Tuomisto A, Väyrynen SA, Klintrup K, Karhu T, Mäkelä J, Herzig KH, Karttunen TJ and Mäkinen MJ: Preoperative anemia in colorectal cancer: Relationships with tumor characteristics, systemic inflammation, and survival. Sci Rep 8: 1126, 2018.

8. Tabung FK, , Liu L, Wang W, Fung TT, Wu K, Smith-Warner SA, Cao Y, Hu FB, Ogino S, Fuchs CS, et al; Association of dietary inflammatory potential with colorectal cancer risk in men and women. JAMA Oncol 4: 366-373, 2018.

9. Gu, Y Chen T, Li G, Yu X, Lu Y, Wang H and Teng L: lncRNAs: emerging biomarkers in gastric cancer. Future Oncol 11: 2427-2441,

10. Ma N, Li S, Zhang Q, Wang H, Qin H and Wang S: Long non-coding RNA GAS5 inhibits ovarian cancer cell proliferation via the control of microRNA-21 and SPRY2 expression. Exp Ther Med 16: 73-82, 2018.

11. Ma Z, Peng P, Zhou J, Hui B, Ji H, Wang J and Wang K: Long non-coding RNA SH3PXD2A-AS1 promotes cell progression partly through epigenetic silencing P57 and KLF2 in colorectal cancer. Cell Physiol Biochem 46: 2197-2214, 2018.

12. Jeong G, Bae H, Jeong D, Ham J, Park S, Kim HW, Kang HS and Kim SJ: A Kelch domain-containing KLHDC7B and a long non-coding RNA ST8SIA6-AS1 act oppositely on breast cancer cell proliferation via the interferon signaling pathway. Sci Rep 8: 12922, 2018.

13. Zou Y, Zhong Y, Wu J, Xiao H, Zhang X, Liao X, Li J, Mao X, Liu $Y$ and Zhang F: Long non-coding PANDAR as a novel biomarker in human cancer: A systematic review. Cell Prolif 51: e12422, 2018.

14. Peng W and Fan H: Long non-coding RNA PANDAR correlates with poor prognosis and promotes tumorigenesis in hepatocellular carcinoma. Biomed Pharmacother 72: 113-118, 2015.

15. Rivandi M, Pasdar A, Hamzezadeh L, Tajbakhsh A, Seifi S, Moetamani-Ahmadi M, Ferns GA and Avan A: The prognostic and therapeutic values of long noncoding RNA PANDAR in colorectal cancer. J Cell Physiol 234: 1230-1236, 2019.

16. Lu M, Liu Z, Li B, Wang G, Li D and Zhu Y: The high expression of long non-coding RNA PANDAR indicates a poor prognosis for colorectal cancer and promotes metastasis by EMT pathway. J Cancer Res Clin Oncol 143: 71-81, 2017.

17. Li M, Zhao LM, Li SL, Li J, Gao B, Wang FF, Wang SP, Hu XH, Cao J and Wang GY: Differentially expressed lncRNAs and mRNAs identified by NGS analysis in colorectal cancer patients. Cancer Med 7: 4650-4664, 2018. 
18. Dai M, Chen X, Mo S, Li J, Huang Z, Huang S, Xu J, He B, Zou Y, Chen J, et al: Meta-signature lncRNAs serve as novel biomarkers for colorectal cancer: Integrated bioinformatics analysis, experimental validation and diagnostic evaluation. Sci Rep 7: 46572, 2017.

19. Xu J, Zhang R and Zhao J: The Novel Long Noncoding RNA TUSC7 inhibits proliferation by sponging miR-211 in colorectal cancer. Cell Physiol Biochem 41: 635-644, 2017.

20. Ren W, Chen S, Liu G, Wang X, Ye H and Xi Y: TUSC7 acts as a tumor suppressor in colorectal cancer. Am J Transl Res 9: 4026-4035, 2017.

21. Livak KJ and Schmittgen TD: Analysis of relative gene expression data using real-time quantitative PCR and the 2(-Delta Delta C(T)) Method. Methods 25: 402-408, 2001.

22. Chang ZW, Jia YX, Zhang WJ, Song LJ, Gao M, Li MJ, Zhao RH Li J,Zhong YL, Sun QZ, et al: IncRNA-TUSC7/miR-224 affected chemotherapy resistance of esophageal squamous cell carcinoma by competitively regulating DESC1. J Exp Clin Cancer Res 37: $56,2018$.

23. Ma XL, Zhu WD, Tian LX, Sun WD, Shang F, Lin QT and Zhang HQ: Long non-coding RNA TUSC7 expression is independently predictive of outcome in glioma. Eur Rev Med Pharmacol Sci 21: 3605-3610, 2017.

24. Qi P, Xu MD, Shen XH, Ni SJ, Huang D, Tan C, Weng WW, Sheng WQ, Zhou XY and Du X: Reciprocal repression between TUSC7 and miR-23b in gastric cancer. Int J Cancer 137: 1269-1278, 2015.

25. Wang Y, Liu Z, Yao B, Dou C, Xu M, Xue Y, Ding L, Jia Y, Zhang $\mathrm{H}$, Li Q, et al: Long non-coding RNA TUSC7 acts a molecular sponge for miR-10a and suppresses EMT in hepatocellular carcinoma. Tumour Biol 37: 11429-11441, 2016.

26. Wang Z, Jin Y, Ren H, Ma X, Wang B and Wang Y: Downregulation of the long non-coding RNA TUSC7 promotes NSCLC cell proliferation and correlates with poor prognosis. Am J Transl Res 8: 680-687, 2016.

27. Li N, Shi K and Li W: TUSC7: A novel tumor suppressor long non-coding RNA in human cancers. J Cell Physiol 233: 6401-6407, 2018.

28. Shang C, Guo Y, Hong Y and Xue YX: Long non-coding RNA TUSC7, a target of miR-23b, plays tumor-suppressing roles in human gliomas. Front Cell Neurosci 10: 235, 2016.

29. Li T, Huang H, Shi G, Zhao L, Li T, Zhang Z, Liu R, Hu Y, Liu H, Yu J, et al: TGF- $31-S O X 9$ axis-inducible COL10A1 promotes invasion and metastasis in gastric cancer via epithelial-to-mesenchymal transition. Cell Death Dis 9: 849, 2018.
30. Song N, Zhong J, Hu Q, Gu T, Yang B, Zhang J, Yu J, Ma X, Chen Q, Qi J, et al: FGF18 Enhances Migration and the epithelial-mesenchymal transition in breast Cancer by regulating Akt/GSK3 $\beta / \beta$-catenin signaling. Cell Physiol Biochem 49: 1019-1032, 2018.

31. Liu YW, Sun M, Xia R, Zhang EB, Liu XH, Zhang ZH, $\mathrm{Xu}$ TP, De W, Liu BR and Wang ZX: LincHOTAIR epigenetically silences miR34a by binding to PRC2 to promote the epithelial-to-mesenchymal transition in human gastric cancer Cell Death Dis 6: e1802, 2015.

32. Pan C, Yao G, Liu B, Ma T, Xia Y, Wei K, Wang J, Xu J, Chen L and Chen Y: Long noncoding RNA FAL1 promotes cell proliferation, invasion and epithelial-mesenchymal transition through the PTEN/AKT signaling axis in non-small cell lung cancer. Cell Physiol Biochem 43: 339-352, 2017.

33. Li J, Wang YM and Song YL: Knockdown of long noncoding RNA AB073614 inhibits glioma cell proliferation and migration via affecting epithelial-mesenchymal transition. Eur Rev Med Pharmacol Sci 20: 3997-4002, 2016.

34. Zhang W, Yuan W, Song J, Wang S and Gu X: lncRna CPS1-IT1 suppresses cell proliferation, invasion and metastasis in colorectal cancer. Cell Physiol Biochem 44: 567-580, 2017.

35. Wang TH, Yu CC, Lin YS, Chen TC, Yeh CT, Liang KH, Shieh TM, Chen CY and Hsueh C: Long noncoding RNA CPS1-IT1 suppresses the metastasis of hepatocellular carcinoma by regulating HIF- $1 \alpha$ activity and inhibiting epithelial-mesenchymal transition. Oncotarget 7: 43588-43603, 2016.

36. Xue J, Liao L, Yin F, Kuang H, Zhou X and Wang Y: IncRNA AB073614 induces epithelial- mesenchymal transition of colorectal cancer cells via regulating the JAK/STAT3 pathway. Cancer Biomark 21: 849-858, 2018.

37. Zhao S, Zhang Y, Zheng X, Tu X, Li H, Chen J, Zang Y and Zhang J: Loss of MicroRNA-101 promotes epithelial to mesenchymal transition in hepatocytes. J Cell Physiol 230: 2706-2717, 2015.

38. Jiang X, Zhou Y, Sun AJ and Xue JL: NEAT1 contributes to breast cancer progression through modulating miR-448 and ZEB1. J Cell Physiol 233: 8558-8566, 2018.

39. de Barrios O, Győrffy B, Fernández-Aceñero MJ, Sánchez-Tilló E, Sánchez-Moral L, Siles L, Esteve-Arenys A, Roué G, Casal JI, Darling DS, et al: ZEB1-induced tumourigenesis requires senescence inhibition via activation of DKK1/mutant $\mathrm{p} 53 / \mathrm{Mdm} 2 / \mathrm{CtBP}$ and repression of macroH2A1. Gut 66: 666-682, 2017 